\title{
Important differences between quality of life and health status in elderly patients suffering from critical limb ischemia
}

This article was published in the following Dove Press journal:

Clinical Interventions in Aging

\author{
Stijn L Steunenberg' \\ Jolanda de Vries ${ }^{2,3}$ \\ Jelle W Raats' \\ Nathalie Verbogt' \\ Paul Lodder ${ }^{2,4}$ \\ Geert-Jan van Eijck ${ }^{5}$ \\ Eelco J Veen' \\ Hans GW de Groot ${ }^{\prime}$ \\ Gwan $\mathrm{H} \mathrm{Ho}$ \\ Lijckle van der Laan' \\ 'Department of Surgery, Amphia \\ Hospital, Breda, The Netherlands; \\ ${ }^{2}$ Department of Medical and Clinical \\ Psychology, Tilburg University, Tilburg, \\ The Netherlands; ${ }^{3}$ Department of \\ Medical Psychology, ETZ, Tilburg, The \\ Netherlands; ${ }^{4}$ Department of \\ Methodology and Statistics, Tilburg \\ University, Tilburg, The Netherlands; \\ ${ }^{5}$ Department of Surgery, Bravis Hospital, \\ Roosendaal, The Netherlands
}

Introduction: Critical limb ischemia (CLI) patients are often of advanced age with reduced health status (HS) and quality of life (QoL) at baseline. Physical health is considered as the most affected domain due to reduced mobility and ischemic pain. QoL and HS are often used interchangeably in the current literature. HS refers to objectively perceived physical, psychological, and social functioning and in assessing QoL, change is measured subjectively and can only be determined by the individual since it concerns patients' evaluation of their functioning. It is important to distinguish between QoL and HS, especially in the concept of shared decision-making when the opinion of the patient is key. Goal of this study was to examine and compare QoL and HS in elderly CLI patients in relation to the used therapy, with a special interest in conservatively treated patients.

Methods: Patients suffering from CLI and $\geq 70$ years old were included in a prospective study with a follow-up period of 1 year. Patients were divided into three groups; endovascular revascularization, surgical revascularization, and conservative therapy. The WHOQoLBref was used to determine QoL, and the 12-Item Short Form Health Survey was used to evaluate HS at baseline, 5-7 days, 6 weeks, 6 months, and 1 year.

Results: Physical QoL of endovascularly and surgically treated patients showed immediate significant improvement during follow-up in contrast to delayed increased physical HS at 6 weeks and 6 months $(P<0.001)$. Conservatively treated patients showed significantly improved physical QoL at 6 and 12 months $(P=0.02)$ in contrast to no significant improvement in physical HS. Conclusion: This study demonstrates that QoL and HS are indeed not identical concepts and that differentiating between these two concepts could influence the choice of treatment in elderly CLI patients. Discriminating between QoL and HS is, therefore, of major importance for clinical practice, especially to achieve shared decision-making.

Keywords: critical limb ischemia, elderly, quality of life, health status

\section{Introduction}

Treatment outcome rates in critical limb ischemia (CLI) patients traditionally focus on primary patency, limb salvage, and mortality. ${ }^{1}$ Reports on patient-reported outcome measures (PROMS) appear to be an important primary endpoint in addition to traditional outcome results. Especially in elderly patients with limited life expectancy, these PROMS offer important information regarding the success of treatment from a patient's perspective and could help in shared decision-making. ${ }^{2,3}$

Functional status is used as a PROMS to assess patient's daily activities and their level of physical autonomy. ${ }^{4-8}$ The major disadvantage of functional status is that
Correspondence: Stijn L Steunenberg Department of Surgery, Amphia Hospital, Molengracht 21, Breda $4818 \mathrm{CK}$, The Netherlands

Tel +3I 765954246

Fax +31 765953818

Email stijnsteunenberg@hotmail.com 
solely patient's daily activities and their autonomy level are assessed, without taking patients satisfaction with functioning into account. Another PROMS is quality of life (QoL), a term that is used confusingly in the current literature. ${ }^{9-11}$ It is often interchangeably used with the term health status (HS). HS refers to objectively perceived physical, psychological, and social functioning. We concur with the WHOQOL (World Health Organization Quality Of Life) group's definition of QoL. They stated that QoL refers to a patient's experiences, beliefs, expectations, and perceptions regarding physical, psychological, and social functioning. In assessing QoL, change is measured subjectively and can only be determined by the individual since it concerns patients' evaluation of their functioning. ${ }^{12}$

PROMS could help physicians in the treatment selection, although revascularization is still considered as cornerstone of the treatment. ${ }^{13,14}$ However, $50 \%$ of the elderly CLI patients are deemed unfit or have unsuitable anatomical lesions for endovascular or surgical procedures. ${ }^{13}$ Concerning the novel concept of "do no further harm", conservative treatment may be an option in these elderly CLI patients. To give this treatment option a chance in the therapy schedule of elderly CLI patients, it is important to know the subjectively measured QoL of these patients compared to the objectively measured HS. The goal of this study was to examine and compare QoL (WHOQoL-Bref) in relation to HS (SF-12) in elderly patients suffering from CLI in relation to therapy and especially conservative treatment.

\section{Methods}

\section{Patient selection}

The methods of this study were published previously. ${ }^{15}$ In summary, patients suffering from CLI classified as Rutherford 4-6 and $\geq 70$ years old were included in two hospitals (Amphia hospital and Bravis hospital, The Netherlands) between January 2012 and February 2016 in a prospective observational cohort study database. No ethical approval was necessary because treatment selection was based on standard protocol without experimental treatments. Only the follow-up and questionnaires were added to the treatment, and informed consent was obtained and signed before the treatment started. This statement was approved by the medical ethical committee of the Amphia hospital.

\section{Treatment selection}

Vascular surgeons and certified interventionists determined treatment of choice in a multidisciplinary vascular conference. Patients were divided patients into three groups according to the used primary treatment (endovascular revascularization, surgical revascularization, and conservative therapy). Conservative treatment (non-revascularization therapy) consisted of intensive wound care, pain control with optimal pharmacological treatment, antibiotics if the infection was suspected, and minor amputations, defined as amputation below the ankle if necessary. ${ }^{16}$

\section{Quality of life}

QoL was measured using the WHOQOL-Bref questionnaire. This questionnaire was chosen because it could be used in the whole population and correspond with the subjective character of QoL. ${ }^{12}$ It contains 26 items with a 5-point Likert type response scale, divided into four domains (physical health, psychological health, social relationships, environment) and a general QoL facet. ${ }^{17}$ The physical and psychological domain were analyzed in this study (13 items), and scores in each domain are ranged between 4 and 20. The physical health domain concentrates on questions about energy, sleep, pain, and mobility. Psychological health contains questions about positive and negative feelings, body image, and self-esteem.

\section{Health status}

The 12-Item Short Form Health Survey (SF-12) was used to determine HS. ${ }^{18}$ The SF-12 is the short version of the SF-36, used in the general population to assess HS, and each domain is scored in a range between 0 and 100 . The SF-12 questionnaire consists of 12 questions that provided information about physical and mental functioning.

\section{Follow-up}

Follow-up was performed at 1 week, 6 weeks, 6 months, and 1 year after the initial therapy. The questionnaires were completed either in the outpatient clinic or by telephone interview.

\section{Statistics}

Statistical analyses were performed by using IBM SPSS 22.0. Analysis of variance was used to compare the three groups. Linear mixed models were performed with five time points to examine the outcome differences between baseline and postoperative QoL and HS between the three included treatment groups. The advantage of these methods was that cases with missing values could be included and time effects could be modeled with greater flexibility. Variables such as treatment modality, time of follow-up, 
and the interaction between these two variables were examined. Significance was evaluated at $P<0.05$ after we adjusted for multiple testing based on the false discovery rate procedure. ${ }^{19}$ Pearson correlations were calculated between QoL scores and HS scores at baseline. Common variance of the two questionnaires was determined using the scores of the Pearson correlation.

\section{Results}

A total of 387 patients aged $>70$ were diagnosed with CLI in the inclusion period. One hundred and ninety-five patients (50\%) were included in this study. The other 192 patients were excluded because of a primary amputation, recently diagnoses malignancy, inadequate understanding of the Dutch language, cognitive impairment or rejection to contribute in the study. Patients were divided into three treatment groups; endovascular revascularization $(\mathrm{n}=82)$, surgical revascularization $(n=67)$, and conservative treatment $(\mathrm{n}=46)$. Baseline characteristics are presented in Table 1.

\section{Physical domain}

Pearson correlation was used to measure the correlation between physical QoL domain and physical HS domain and shows a moderate correlation of 0.66 with a common variance of $45 \%$. Table 2 presents the QoL and HS scores of the physical domain. There was an immediate significant improvement of physical QoL in patients undergoing endovascular and surgical treatment at 5-7 days $(P<0.001)$ that persisted during the first year of follow-up. This effect occurred in the physical HS domain at 6 weeks in surgically treated patients $(P<0.001)$ and at 6 months in endovascularly treated patients $(P<0.001)$. Conservatively treated patients reported a significant improved physical QoL at 6 months $(P=0.02)$ and 1 year $(P=0.02)$. However, physical HS showed no significant improvement in the first year of follow-up in conservatively treated patients.

\section{Psychological domain}

Psychological QoL and psychological HS showed a moderate correlation of 0.58 with a common variance of $34 \%$. Psychological QoL and HS scores are presented in Table 2. Surgically treated patients reported an immediate, significant improvement in both psychological QoL and psychological HS. Endovascularly treated patients showed no significant improvement in the psychological QoL domain. In contrast, a significant improvement was found in the psychological HS domain at 6 months $(P=0.02)$, but this significant difference did not maintain at 1 year $(P=0.07)$. Conservatively treated patients showed no significant improvement in QoL or HS regarding the psychological domain.

\section{Discussion}

The goal of this study was to examine and compare QoL and HS in elderly CLI patients in relation to received treatment

Table I Baseline characteristics

\begin{tabular}{|l|l|l|l|}
\hline & Endovascular (n=82) & Surgical (n=67) & Conservative (n=46) \\
\hline Sex (male) & $45(55)$ & $44(66)$ & $21(46)$ \\
Age (median) (IQR) & $81(10)$ & $76(8)$ & $33(9)^{*, \#}$ \\
Rutherford 4 & $22(27)$ & $36(54)$ & $6(13)^{*, \#}$ \\
Rutherford 5/6 & $60(73)$ & $31(46)$ & $40(87)$ \\
\hline Comorbidity & & & \\
Pulmonary comorbidity & $54(68)$ & $28(42)$ & $26(58)^{*}$ \\
Cardiac comorbidity & $62(76)$ & $36(54)$ & $36(78)^{*, \#}$ \\
Neurologic comorbidity & $23(28)$ & $19(28)$ & $21(46)^{\wedge}$ \\
Arthritis & $21(26)$ & $17(25)$ & $20(44)^{\wedge, \#}$ \\
\hline Vascular risk factors & & & \\
Hypertension & $62(76)$ & $22(58)$ & $29(64)^{*}$ \\
Diabetes & $49(60)$ & $23(34)$ & $23(50)^{*}$ \\
Renal impairment & $55(67)$ & $23(34)$ & $33(72)^{*, \#}$ \\
Current smoking & $15(19)$ & $7(16)^{*, \#}$ \\
\hline
\end{tabular}

Notes: Data are presented as $\mathrm{n}$ and (\%), unless otherwise specified. Pulmonary comorbidity: asthma/chronic obstructive pulmonary disease. Cardiac comorbidity: angina/ myocardial infarction/heart failure/arrhythmias. Neurologic comorbidity: transient ischemic attack/cerebrovascular accident. *Significant difference between endovascular and surgical treated patients $(P<0.05)$. ^Significant difference between endovascular and conservative treated patients $(P<0.05)$. ${ }^{\#}$ Significant difference between surgical and conservative treated patients $(P<0.05)$.

Abbreviation: IQR, interquartile range. 
Table 2 WHOQoL-Bref vs SFI2 according to received treatment

\begin{tabular}{|c|c|c|c|}
\hline & Endovascular $(n=82)$ & Surgical $(n=67)$ & Conservative $(n=46)$ \\
\hline \multicolumn{4}{|l|}{ Physical QoL domain } \\
\hline Baseline & $10.9(2.9)$ & $10.4(2.5)$ & $11.6(2.9)$ \\
\hline $5-7$ days & $11.9(3.1)^{*}$ & $12.1(2.6)^{*}$ & I2.I (2.7) \\
\hline 6 weeks & $12.4(3.3)^{* *}$ & $13.5(3.0)^{* *}$ & $11.8(3.1)$ \\
\hline 6 months & $13.6(3.1)^{* * *}$ & $14.5(2.2)^{* * *}$ & I3.2 (2.6)*** \\
\hline I year & I3.7 (2.8) **** & I $4.9(2.5) * * * *$ & $13.2(2.9) * * * *$ \\
\hline \multicolumn{4}{|l|}{ Physical HS domain } \\
\hline Baseline & $28.9(9.3)$ & $28.0(6.7)$ & $30.2(10.3)$ \\
\hline $5-7$ days & $29.2(9.8)$ & $28.9(7.3)$ & $28.7(8.8)$ \\
\hline 6 weeks & $31.5(10.3)$ & $34.2(9.2) * *$ & $28.3(8.8)$ \\
\hline 6 months & $35.4(9.8) * * *$ & $38.0(9.4) * * *$ & $30.9(8.0)$ \\
\hline I year & $35.3(10.8) * * * *$ & $37.3(9.6) * * * *$ & $31.4(9.3)$ \\
\hline \multicolumn{4}{|l|}{ Psychological QoL domain } \\
\hline Baseline & $14.2(2.5)$ & $14.0(2.4)$ & I4.I (2.5) \\
\hline $5-7$ days & $14.6(1.9)$ & $14.7(2.2)^{*}$ & $14.5(1.6)$ \\
\hline 6 weeks & $14.7(2.1)$ & I $4.8(2.2)^{* *}$ & I4.I (2.3) \\
\hline 6 months & I4.7 (I.8) & $15.2(1.9)^{* * *}$ & $14.5(1.8)$ \\
\hline I year & $14.8(2.1)$ & $15.3(1.9) * * * *$ & $14.0(2.3)$ \\
\hline \multicolumn{4}{|l|}{ Psychological HS domain } \\
\hline Baseline & $37.0(11.7)$ & $36.1(10.3)$ & $40.1(11.2)$ \\
\hline 5-7 days & $40.2(8.3)$ & $40.5(9.0) *$ & $40.5(7.8)$ \\
\hline 6 weeks & $39.6(9.7)$ & $42.0(7.4) * *$ & $40.6(7.5)$ \\
\hline 6 months & $42.4(7.3)$ *** & 44.1 (7.6) $* * *$ & $37.6(7.3)$ \\
\hline I year & $42.5(8.7)$ & $43.9(7.7) * * * *$ & $39.5(10.5)$ \\
\hline
\end{tabular}

Notes: Data are presented as mean and standard deviation. *Significant difference in the treatment group between Baseline and 5-7 days follow-up. **Significant difference in the treatment group between Baseline and 6-week follow-up. ***Significant difference in the treatment group between Baseline and 6-month follow-up. ****Significant difference in the treatment group between Baseline and I-year follow-up. Missing values due to loss of follow-up: $5-7$ days $=22$ missing values, 6 weeks $=20$ missing values, 6 months $=21$ missing values 12 months $=20$ missing values.

Abbreviations: QoL, Quality of Life (WHOQoL-Bref); HS, Health Status (SF-I2).

and especially conservative treatment. According to our results, important difference is present between subjectively measured QoL and objectively measured HS. This difference is especially important in the interpretation of the results of conservatively treated patients. Conservative treatment significantly improves subjectively measured physical QoL, but did not significantly improve objectively measured physical HS. It is important to guide clinical decision-making on the subjective appraisal of health, especially in elderly patients.

Previous research conducted by Breek et al, demonstrated different outcomes across multiple domains for patients suffering from intermittent claudication by comparing the WHOQoL-100 and RAND 36-items health survey. ${ }^{9}$ This difference was explained by the subjective character of the QoL concept in contrast to the objective character of the HS concept. ${ }^{9,10}$ QoL focusses on the patient's experiences, beliefs, expectations, and perceptions and subjectively measures patient's well-being, while HS objectively assesses physical, mental and social functioning. Some differences between similar questions in the SF-12 and WHOQoL-Bref are presented in Table 3 and this contrast could also be explained using the example of elderly patients using the stairs. While it is true that not all elderly patients are able to use stairs, many of these patients have no desire to use stairs as it is no longer a necessity within their life. The SF-12 asks if patients are impaired when walking up stairs and thus, these patients will record a low HS score for this question, despite the fact that they do not consider this impairment to be of significant burden with regard to their mobility or pain. The interpretation by the researcher of this functioning as indicating low HS can lead to a disparity in outcome rates and, therefore, suggests subjective QoL outcome measures to be more appropriate, especially regarding frail, elderly patients.

Pain and impaired mobility are the main symptoms of CLI and are captured in the physical domains of QoL and HS. Therefore, the physical domain may be considered the 
Table 3 Questions asked in the questionnaires

\begin{tabular}{|l|l|l|}
\hline Domain & WHO-QoL Bref & SF-I 2 \\
\hline Physical & $\begin{array}{l}\text { How satisfied are you with your ability to per- } \\
\text { form your daily living activities? }\end{array}$ & $\begin{array}{l}\text { Are you now limited in moderate activities, such as moving a table, pushing a } \\
\text { vacuum cleaner, bowling, or playing golf? Does your health now limit you a lot, } \\
\text { limit you a little or not limit you at all? }\end{array}$ \\
\hline Physical & $\begin{array}{l}\text { To what extent do you feel that physical pain } \\
\text { prevents you from doing what you need to do? }\end{array}$ & $\begin{array}{l}\text { During the past four weeks, how much did pain interfere with your normal } \\
\text { work including both outside the home and housework? }\end{array}$ \\
\hline Psychological & How much do you enjoy life? & $\begin{array}{l}\text { How much of the time during the past four weeks did you have a lot of } \\
\text { energy? }\end{array}$ \\
\hline
\end{tabular}

most important domain to focus on the treatment of CLI patients. ${ }^{14}$ It was in this domain that a striking difference between QoL and HS emerged. Physical QoL exhibited an immediate and significant improvement following endovascular or surgical revascularization, in contrast to the delayed significant improvement in physical HS, observed at 6 months. Conservative treatment or primary amputation are accepted treatment modalities in patients with poor pre-operative living status, and extensive comorbidities. $^{1,4,8,14,15,20}$ Due to a significantly reduced life expectancy, increase in subjectively measures QoL is an important parameter for frail elderly patients in the last phase of their life and transcend traditional outcome measurements such as mortality and patency. ${ }^{3}$ Substantial differences between QoL and HS were observed in conservatively treated patients as these patients did not exhibit a significant increase in their physical HS, although their physical QoL had significantly improved at 6 months and 1 year. Possible explanations for the gained subjective physical functioning of conservatively treated patients could be the effectiveness of pain medication and the hypothesis that elderly patients learn to cope with their limitations in physical functioning in the long term. This result is of major clinical importance, because this result indicates that conservative treatment is an acceptable treatment for selected CLI patients from their point of view. Whereas conservative treatment seems to be a poor treatment option when only focusing on objective physical functioning (HS) and not on patients' subjective evaluation of their functioning (QoL).

Elderly patients are a challenging group to collect PROMS because of the high rate of non-responders, mortality during follow-up and potential difficulty with reading. ${ }^{21}$ Lost to follow-up was reduced by cooperation of a dedicated study coordinator, possibility of telephonically follow-up and use of shortened questionnaires such as WHOQoL-Bref and SF-12. Use of online questionnaires could potentially improve response rates because of an increasing access to the Internet among elderly patients. However, this could also be questioned because of possible browser incompatibility or visual impairment and generalizability among elderly patients is hard. It seems to be worthwhile to offer patients the option to participate using online surveys to potentially reduce lost to follow-up. ${ }^{22}$

The current study has some limitations. Patients were not randomized between the three treatment groups because it is considered unethical to include conservative therapy in randomized controlled trials. However, this prospective study gives a clear view of the differences between HS and QoL in the treatments used for CLI patients in the current clinical practice. These results should be combined with the traditional outcome rates to select the optimal treatment, because of the known high mortality (19-49\%) and limb salvage rates (74-85\%) in elderly CLI patients. ${ }^{3,16,23}$ Also, wound healing in Rutherford five-sixths patients could potentially influence QoL. It would be interesting to investigate if wound closure effect QoL in conservatively treated patients in upcoming research. Due to the use of these shortened questionnaires, only the physical and psychological domains of QoL and HS could be compared. However, physical health is the most important domain for patients suffering CLI, because of ischemic pain and loss of mobility, and is therefore critical to compare across HS and QoL. ${ }^{14}$

\section{Conclusion}

Changes in functioning are measured subjectively in QoL and objectively in HS. This study demonstrates that QoL and HS are indeed not identical concepts and that differentiating between the two concepts could influence the treatment options in elderly CLI patients.

Discriminating between QoL and HS is, therefore, of major importance for clinical practice, especially to achieve shared decision-making. 


\section{Acknowlegment}

This study is co-funded by Nuts-Ohra, the Netherlands.

\section{Disclosure}

Dr Stijn L Steunenberg reports grants from Nuts Ohra, during the conduct of the study. The other authors report no conflicts of interest in this work.

\section{References}

1. Farber A, Eberhardt RT. The current state of critical limb ischemia: a systematic review. JAMA Surg. 2016;151(11):1070-1077. doi:10.1001/ jamasurg.2016.2018

2. Peach G, Holt P, Loftus I, Thompson MM, Hinchliffe R. Questions remain about quality of life after abdominal aortic aneurysm repair. $J$ Vasc Surg. 2012;56(2):520-527. doi:10.1016/j.jvs.2012.02.062

3. Klaphake S, de Leur K, Mulder PGH, et al. Life expectancy and outcome of different treatment strategies for critical limb ischemia in the elderly patients. Ann Vasc Surg. 2018;46:241-248. doi:10.1016/j. avsg.2017.06.141

4. Chisci E, Perulli A, Iacoponi F, et al. Benefit of revascularisation to critical limb ischaemia patients evaluated by a patient-oriented scoring system. Eur $J$ Vasc Endovasc Surg. 2012;43(5):540-547. doi:10.1016/j.ejvs.2012.01.025

5. Vogel TR, Petroski GF, Kruse RL. Functional status of elderly adults before and after interventions for critical limb ischemia. $J$ Vasc Surg. 2014;59(2):350-358. doi:10.1016/j.jvs.2013.08.087

6. Frans FA, Met R, Koelemay MJ, et al. Changes in functional status after treatment of critical limb ischemia. J Vasc Surg. 2013;58 (4):957-65e1. doi:10.1016/j.jvs.2013.04.034

7. Cieri E, Lenti M, De Rango P, Isernia G, Marucchini A, Cao P. Functional ability in patients with critical limb ischaemia is unaffected by successful revascularisation. Eur J Vasc Endovasc Surg. 2011;41(2):256-263. doi:10.1016/j.ejvs.2010.10.014

8. Lejay A, Delay C, Georg Y, et al. Endovascular surgery, open surgery, and primary amputation in nonagenarians presenting with critical limb ischemia. Ann Vasc Surg. 2016;32:25-33. doi:10.1016/j. avsg.2015.11.009

9. Breek JC, de Vries J, van Heck GL, van Berge Henegouwen DP, Hamming JF. Assessment of disease impact in patients with intermittent claudication: discrepancy between health status and quality of life. J Vasc Surg. 2005;41(3):443-450. doi:10.1016/j.jvs.2004.12.042

10. Hamming JF, De Vries J. Measuring quality of life. Br J Surg. 2007;94(8):923-924. doi:10.1002/bjs.5948
11. Steunenberg SL, Raats JW, Te Slaa A, de Vries J, van der Laan L. Quality of life in patients suffering from critical limb ischemia. Ann Vasc Surg. 2016;36:310-319. doi:10.1016/j.avsg.2016.05.087

12. WHO. Development of the World Health Organization WHOQOLBREF quality of life assessment. The WHOQOL Group. Psychol Med. 1998;28(3):551-558.

13. Adam DJ, Beard JD, Cleveland T, et al. Bypass versus angioplasty in severe ischaemia of the leg (BASIL): multicentre, randomised controlled trial. Lancet. 2005;366(9501):1925-1934. doi:10.1016/S0140-6736(05) 67704-5

14. Suckow BD, Goodney PP, Cambria RA, et al. Predicting functional status following amputation after lower extremity bypass. Ann Vasc Surg. 2012;26(1):67-78. doi:10.1016/j.avsg.2011.07.014

15. Steunenberg SL, de Vries J, Raats JW, et al. Quality of life and mortality after endovascular, surgical, or conservative treatment of elderly patients suffering from critical limb ischemia. Ann Vasc Surg. 2018;51:95-105. doi:10.1016/j.avsg.2018.02.044

16. Brosi P, Dick F, Do DD, Schmidli J, Baumgartner I, Diehm N. Revascularization for chronic critical lower limb ischemia in octogenarians is worthwhile. J Vasc Surg. 2007;46(6):1198-1207. doi:10.1016/j.jvs.2007.07.047

17. Trompenaars FJ, Masthoff ED, Van Heck GL, Hodiamont PP, De Vries J. Content validity, construct validity, and reliability of the WHOQOL-Bref in a population of Dutch adult psychiatric outpatients. Qual Life Res. 2005;14(1):151-160.

18. Ware J Jr., Kosinski M, Keller SD. A 12-item short-form health survey: construction of scales and preliminary tests of reliability and validity. Med Care. 1996;34(3):220-233.

19. Benjamini Y, Hochberg Y. Controlling the false discovery rate: a practical and powerful approach to multiple testing. $J$ R Stat Soc. 1995;57(1):289-300.

20. Thomas AR, Raats JW, Lensvelt MM, de Groot HG, Veen EJ, van der Laan L. Conservative treatment in selected patients with severe critical limb ischemia. World J Surg. 2015;39(8):2090-2095. doi:10.1007/s00268-015-3069-6

21. Alabi O, Roos M, Landry G, Moneta G. Quality of life assessment as an outcomes measure in critical limb ischemia. J Vasc Surg. 2017;65 (2):571-578. doi:10.1016/j.jvs.2016.08.097

22. Remillard M, Mazor K, Cutrona S, Gurwitz J, Tjia J. Systematic review of the use of online questionnaires of older adults. $J \mathrm{Am}$ Geriatr Soc. 2014;62(4):696-705. doi:10.1111/jgs.12747

23. Iida O, Takahara M, Soga Y, et al. Prognostic impact of revascularization in poor-risk patients with critical limb ischemia: the PRIORITY registry (Poor-risk patients with and without revascularization therapy for critical limb ischemia). JACC Cardiovasc Interv. 2017;10(11):1147-1157. doi:10.1016/j.jcin.2017.03.012
Clinical Interventions in Aging

\section{Publish your work in this journal}

Clinical Interventions in Aging is an international, peer-reviewed journal focusing on evidence-based reports on the value or lack thereof of treatments intended to prevent or delay the onset of maladaptive correlates of aging in human beings. This journal is indexed on PubMed Central, MedLine, CAS, Scopus and the Elsevier
Bibliographic databases. The manuscript management system is completely online and includes a very quick and fair peer-review system, which is all easy to use. Visit http://www.dovepress.com/ testimonials.php to read real quotes from published authors. 